\title{
Ranking the knowledge management enablers based on University Academic Members, Staff and Students using AHP Method
}

\author{
Gholamreza Jandaghi ${ }^{1, *}$, Hamid Reza Irani ${ }^{1}$, Ehssan Jandaghi ${ }^{2}$, \\ Zeinab Sadat Mousavi ${ }^{1}$, Maryam Davoodavabi ${ }^{1}$ \\ ${ }^{1}$ Faculty of Management and Accountancy, Farabi Campus, University of Tehran, Iran \\ 2Iran University of Science and Technology, Tehran, Iran \\ *E-mail address: jandaghi@ut.ac.ir
}

\begin{abstract}
Knowledge management can play a vital role in increasing the efficiency and effectiveness of organizations. The earnings from utilizing knowledge management has caused that most organizations try to execute this process. In this study, we aim to assess the ranking and weights of knowledge management enablers based on the academic members, staff and student in management schools of Qom province in Iran. The results showed that the organizational culture has the most important position while the organizational structure has the least important position in knowledge management in universities. Using a group AHP weighting method resulted in highest weight for organizational culture and lowest weight for organizational culture in developing knowledge management in educational organizations.
\end{abstract}

Keywords: Knowledge management Enablers; faculty members; Students; staff; AHP method

\section{INTRODUCTION}

In recent years, the role of knowledge in organizational improvement is clarified more that before and most organizations have found a serious propensity to manage the knowledge. Due to an increase in knowledge value, it seems rational to create an opportunity for a competitive advantage by managing the knowledge effectively (Duffy and John, 2000).

Knowledge management is considered by many authors as a key strategy to achieve organizational success and survival in today hyper competition and unpredictable ambience. People can achieve a new thinking pattern by which they can redefine the affairs and the styles to perform them if they can learn and use knowledge in organizations creatively. Therefore, knowledge management should have learning perspectives and tools. A well - established knowledge management system can provide organizations and even individuals with sustainable profitability (Hamidizadeh, 2008). 


\section{KNOWLEDGE FLOW}

Drucker defines knowledge as "information which changes someone or something or enables an individual or institute for an effective initiative" (Claver - Corte's et al, 2007). Fleming divides human mental properties into different levels by considering its conception and relation namely data, information, knowledge and wisdom.

Therefore, a main discussion on knowledge management is to understand data, information, knowledge and wisdom and their interactions. One can use knowledge flow to understand and define knowledge. Knowledge flow is a set of processes and activities by which data, information, knowledge and wisdom are changed from one position to another. Thus, any discussion on knowledge should be started from data (Adli, 2005: 21).

Knowledge process and flow model is provided by Spengler. He provided his model based on knowledge flow and time horizon. Knowledge flow is explainable through Figure 1.

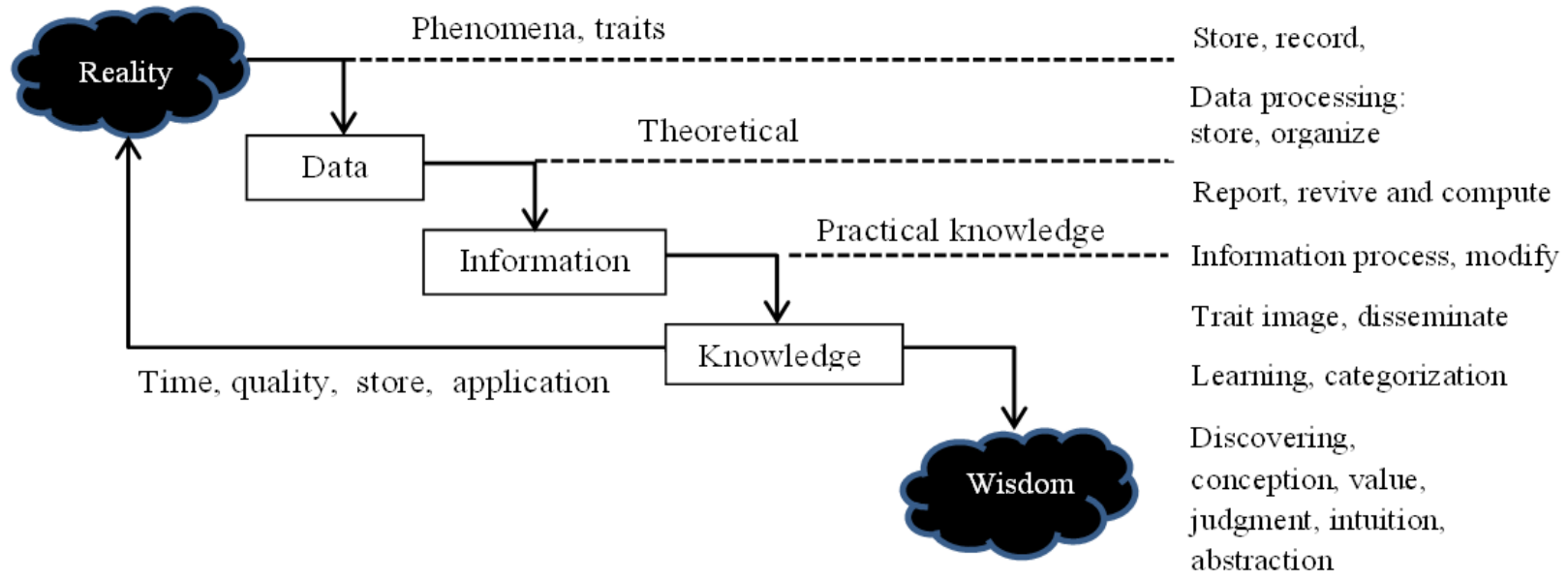

Figure 1. Knowledge flow and knowledge process.

According to above figure, reality relates to objects and phenomena while data is their traits.

- Data is responsible to show, record, store and keep such traits.

- Information is theoretical knowledge and is acquired through data processing operation. It includes organizing, storing, etc.

- Knowledge is defined as practical knowledge and is the outcome of information processing operation.

- Wisdom is wisdom "when we know it." Knowledge impacts on wisdom through such activities as discovery, intuition, value and experience.

Above steps would lead into changes in knowledge processing. Such changes are accompanied with processing in each step (Suri, 2007: 129-130). 


\section{KNOWLEDGE MANAGEMENT ENABLERS}

To execute and use knowledge management processes in an organization, there needs physical and rational changes as well as certain structures in conducting operations. Such prerequisites are introduced to establish knowledge management as the infrastructure of knowledge management and its enablers to which we address below. In fact, knowledge management enablers are considered as factors to measure the readiness of organizations to execute knowledge management (Jalaldeen et al, 2009; Gaffoor, 2008, Quoin et al, 2005; Holt et al, 2007). In present study, knowledge management enablers are used as factors to measure the readiness of organizations to execute knowledge management.

Knowledge management enablers in an organization encourage knowledge development, knowledge generation inside the organization as well as sharing and protecting it (Yeh et al, 2006). In fact, knowledge enabler is the capability of an organization to expand its own knowledge by which it protects its organizational knowledge and encourages knowledge generation culture as well as knowledge sharing among organizational members. Executing and using knowledge management would be easier and simpler if such vital enablers exist in the organization and, consequentially, organizations are able to use their resources more efficiently and effectively (Gaffoor, 2008; Yeh et al, 2006).

Table 1. Comparing the models to knowledge management empowerments.

\begin{tabular}{|c|c|c|c|c|c|c|c|c|c|c|}
\hline $\begin{array}{c}\text { KM } \\
\text { empowerments }\end{array}$ & 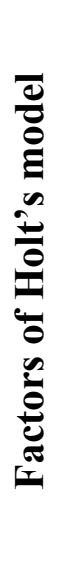 & 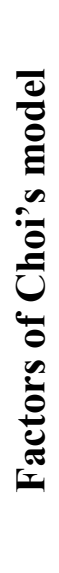 & 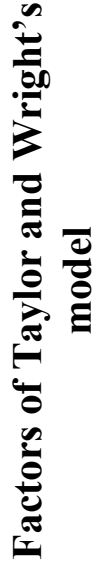 & 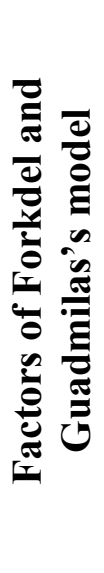 & 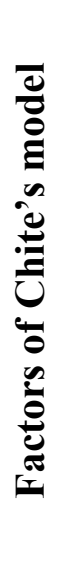 & 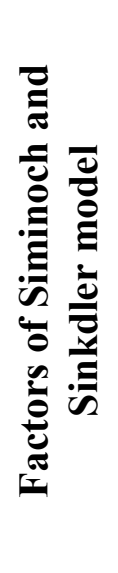 & 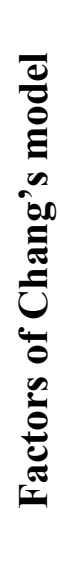 & 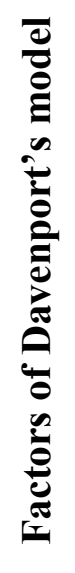 & 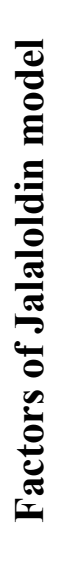 & 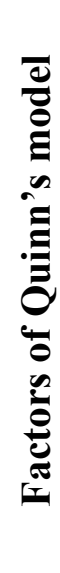 \\
\hline $\begin{array}{c}\text { Organizational } \\
\text { culture }\end{array}$ & $\sqrt{ }$ & $\sqrt{ }$ & $\sqrt{ }$ & $\sqrt{ }$ & $\sqrt{ }$ & $\sqrt{ }$ & - & $\sqrt{ }$ & $\sqrt{ }$ & $\sqrt{ }$ \\
\hline $\begin{array}{l}\text { Organizational } \\
\text { Structure }\end{array}$ & - & $\sqrt{ }$ & - & $\sqrt{ }$ & - & $\sqrt{ }$ & - & $\sqrt{ }$ & $\sqrt{ }$ & $\sqrt{ }$ \\
\hline $\begin{array}{c}\text { IT } \\
\text { infrastructure }\end{array}$ & - & $\sqrt{ }$ & $\sqrt{ }$ & $\sqrt{ }$ & $\sqrt{ }$ & $\sqrt{ }$ & $\sqrt{ }$ & $\sqrt{ }$ & $\sqrt{ }$ & $\sqrt{ }$ \\
\hline $\begin{array}{c}\text { Managerial } \\
\text { initiatives }\end{array}$ & $\sqrt{ }$ & $\sqrt{ }$ & $\sqrt{ }$ & $\sqrt{ }$ & $\sqrt{ }$ & $\sqrt{ }$ & $\sqrt{ }$ & $\sqrt{ }$ & - & $\sqrt{ }$ \\
\hline HR & $\sqrt{ }$ & - & $\sqrt{ }$ & - & - & $\sqrt{ }$ & $\sqrt{ }$ & - & $\sqrt{ }$ & $\sqrt{ }$ \\
\hline
\end{tabular}

There is an increase in the number of knowledge management enabler models and organizational readiness to execute knowledge management in recent years. Today, each 
organization measures its readiness to execute or implement transformation projects in various IT fields in order to prevent capital wasting. To the same reason, paramount models are developed to measure organizational readiness in various fields. Table 1 outlines knowledge management enabler models and organizational readiness to execute knowledge management more relevant to present study.

\section{RESEARCH GOALS}

Present study aims to rank and weight the knowledge management enablers in educational institutions based on the opinion of academic members, staff and students in management schools of Qom Province in Iran

\section{RESEARCH METHODOLOGY}

Research statistical population consists of all academic members, staff and student in Management schools of Qom province in Iran. There are several universities in Qom province of which 5 universities have management school. These universities are Farabi Campus of University of Tehran, Qom university, Hazrat Masoumeh University, Payam noor university and Islamic Azad university. The sample consists of 520 from the population which has been drawn using random stratified sampling method. We used a questionnaire to gather the required data for pairwise comparison of enablers. We distributed 520 questionnaires of which 398 were returned and 390 were used in the analysis. We used group AHP methodology for ranking the knowledge management enablers.

\section{RESULTS}

After the questionnaire was administered to sample individuals where they compared the five knowledge management enablers pairwise, the group AHP( Analytic Hierarchy Process) was used to derive the weights of the enablers. The results are shown in tables 2 and 3.

Table 2. Ranking of the knowledge management enablers based on the sample.

\begin{tabular}{|c|c|c|c|c|}
\hline KM empowerments & 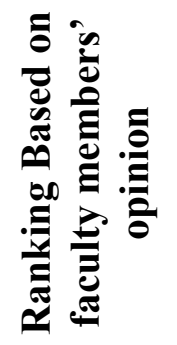 & 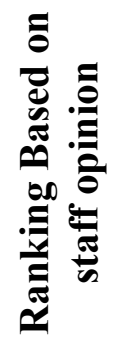 & 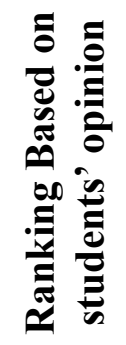 & 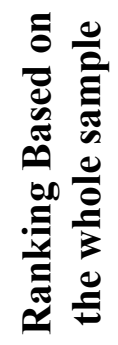 \\
\hline Organizational culture & 1 & 1 & 1 & 1 \\
\hline
\end{tabular}




\begin{tabular}{|c|c|c|c|c|}
\hline HR & 3 & 2 & 2 & 2 \\
\hline Managerial initiatives & 2 & 3 & 3 & 3 \\
\hline IT infrastructure & 4 & 4 & 4 & 4 \\
\hline Organizational Structure & 5 & 5 & 5 & 5 \\
\hline
\end{tabular}

Table 3. Weights of knowledge management enablers based on the sample.

\begin{tabular}{|c|c|c|c|c|c|}
\hline Weights & 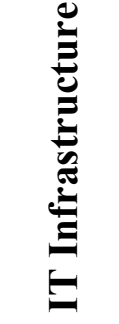 & $\underline{\underline{I}}$ & 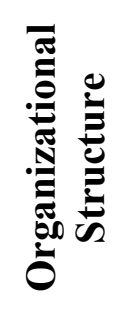 & 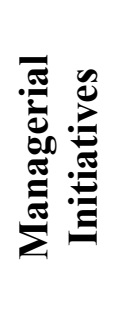 & 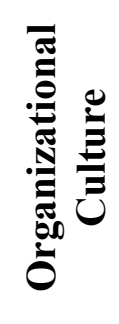 \\
\hline Based on Faculty members' opinion & 0.117 & 0.136 & 0.182 & 0.155 & 0.410 \\
\hline Based on Faculty staff opinion & 0.132 & 0.144 & 0.181 & 0.240 & 0.304 \\
\hline Based on Faculty students' opinion & 0.127 & 0.158 & 0.166 & 0.182 & 0.367 \\
\hline Based on the whole sample & 0.127 & 0.155 & 0.169 & 0.182 & 0.366 \\
\hline
\end{tabular}

As can be seen from Tables 2 and 3, the organizational culture has the first rank with the highest weight in knowledge management process in universities. The IT infrastructure has the lowest weight in knowledge management process which shows that despite of the importance of this enabler, the organizational culture has a more important role.

\section{DISCUSSION AND CONCLUSIONS}

In the past, organizations were looking for acquiring and finding knowledge information. Now, they are facing with paramount information and data. In many cases, the issue is how to use such information rightly. Perhaps, it is for the same reason that knowledge management has found a special status in management literature and has attracted connoisseurs to develop its techniques and guidelines (Davenport and Prusak, 2000: 3). Holt et al (2007) have only considered the status quo of organizational members as the readiness to accept knowledge management process. Their manuals are more concentrated on knowledge sharing and human factories and they do not measure organizational physical and logical infrastructures such as organizational structure and information technology (IT) that are among affecting factors in knowledge management acceptance process. Additionally, more researches have addressed 
human and organizational factors separately which needs a collective review. In fact, mere focus on technical factors and communicational infrastructures cannot alone guarantee the success of knowledge management plans and management should be able to overcome harder problems such as social and cultural ones with regard to organizational knowledge management (Mohayidin, 2007) since in contrary to information management infrastructure, needed infrastructure for knowledge management is not merely physical. As an organization means a group of people who work in a structured context through a joint target, considering only organizational factors is not adequate in evaluating organizational readiness to execute knowledge management process. Therefore, the readiness of organizational members should be evaluated in accepting and executing knowledge management. According to conducted studies in existing literature and by comparative study of knowledge management empowerments to each model as seen in Table 1, all such factors as "organizational culture", "organizational structure", "IT infrastructure", "managerial initiatives" and "human resources" are introduced in present study as the most complete knowledge management empowerments to execute knowledge management. In educational organizations like universities, as shown in Table 2 and Table 3, the organizational culture plays the most important roles in knowledge management process.

\section{ACKNOWLEDGEMENT}

This Research has been done by financial support of University of Tehran, Grant number 9660939/1/01.

\section{References}

[1] Duffy \& Jan, The Information Management Journal 34(2) (2000) 62-66.

[2] Hamidizadeh Mohammad Reza (2008). "Training guidelines to disseminate knowledge management", HR Management in Oil Industry Quarterly, Energy International Studies Institute, Vol. 1.

[3] Claver-Corte's Enrique, Zaragoza-Sa'ez Patrocinio, Pertusa-Ortega Eva, Journal of Knowledge Management 11(4) (2007) 45-57.

[4] Adli Fariba (2005). Knowledge management: movement toward cross-knowledge, Tehran, Andisheh Publications.

[5] Suri Hassan (2007), Reengineering in Iranian organizations, Tehran, Rasa Publications.

[6] Jalaldeen Reza, et al. (2009). "Organizational Readiness and its Contributing Factors to Adopt KM Processes: A Conceptual Model", Communications of the IBIMA.

[7] Gaffoor Shamin (2008). "Assessing readiness for the implementation of knowledge management in local government: The case of Stellenbosch Municipality", These for de degree of Master of Commerce at Stellenbosch University, School of Public Management and Planning, Faculty of Economic and Management Sciences.

[8] Quoin Tan Yit, et al. (2005). "Knowledge Management Readiness in Organization: A Case of Public Sector in Malaysia", International Conference of Knowledge Management (ICKM). 
[9] Holt D. T., Bartczak S. E., Clark S. W., Trent M. N., The development of an instrument to measure readiness of knowledge management, Knowledge Management Research \& Practice (2007) 75-92.

[10] Yeh Ying Jung, Lai Sun Quae, Ho Chin. Tsange, Industrial Management \& Data Systems 106(6) (2006) 793-810.

[11] Davenport T., Prusak L. (1998), "Working knowledge-How organizations manage what they know", Harvard Business School Press: Boston, MA

[12] Mohd Ghazali Mohayidin, Nor Azirawani, Man Norfaryanti Kamaruddin, Mar Idawati Margono, The Electronic Journal of Knowledge Management 5(3) (2007) 301-312.

[13] Mohsen Mehrara, Maysam Musai, International Letters of Social and Humanistic Sciences 5 (2013) 55-62.

[14] Rezgar Mohammadi, Ezatullah Naderi, International Letters of Social and Humanistic Sciences 9 (2013) 22-30.

[15] Morteza Ziaee, International Letters of Social and Humanistic Sciences 9 (2014) 57-65.

[16] Sakineh Ghayazi, Faranak Omidian, Mohammed Hosseinpoor, International Letters of Social and Humanistic Sciences 10(1) (2014) 51-61. 